ISSN: 1858-4837; E-ISSN: 2598-019X

Volume 17, Nomor 1 (2022),

https://jurnal.uns.ac.id/region

DOI: 10.20961/region.v17i1.44172

\title{
Kesesuaian Rencana Tata Ruang Wilayah (RTRW) berbasis bahaya banjir menggunakan analisis hierarki proses di Kabupaten Kuningan
}

\author{
Suitability of flood hazard-based Spatial Planning process hierarchy analysis in \\ Kuningan Regency
}

\author{
F D Haris ${ }^{1}$, S R P Sitorus ${ }^{2}$, dan B Tjahjono ${ }^{2}$ \\ ${ }^{1}$ Program Studi IImu Pengelolaan Sumberdaya Alam dan Lingkungan, Institut \\ Pertanian Bogor \\ ${ }^{2}$ Sekolah Pascasarjana Institut Pertanian Bogor
}

Corresponding author's email: fikridwiharis47@gmail.com

\begin{abstract}
Abstrak. Indonesia memiliki kondisi alam yang tergolong rawan terhadap bencana alam. Penyebab terjadinya bencana di Indonesia bisa disebabkan oleh faktor alam dan faktor manusia. Adapun faktor manusia berupa penerapan penggunaan lahan tidak mempertimbangkan karakteristik bentang alam. Kabupaten Kuningan merupakan salah satu wilayah administratif yang terkena dampak bencana (banjir) akibat penggunaan lahan yang tidak mempertimbangkan karakteristik bentang lahan. Tujuan penelitian ini adalah untuk mengetahui kesesuaian antara pola ruang RTRW Kabupaten Kuningan (2011-2031) dengan daerah bahaya bencana banjir di Kabupaten Kuningan. Metode yang digunakan pada penelitian ini yaitu Analysis Hierarchy Process (AHP) dan pairwise comparison untuk penentuan skor faktor penyebab banjir dan longsor, interpretasi citra Sentinel visual tahun 2018 untuk menentukan penggunaan lahan di Kabupaten Kuningan serta metode analisis spasial melalui teknik overlay untuk menentukan daerah bahaya banjir dan longsor. Hasil penelitian menunjukkan bahwa faktor bahaya banjir yang mempunyai bobot terbesar hingga terkecil menurut para pakar berturut-turut adalah curah hujan, kemiringan lereng, penggunaan lahan, jenis tanah, dan elevasi. Bahaya banjir dan longsor terdiri atas 3 kelas, yaitu rendah, sedang, tinggi. Hasil overlay antara faktor-faktor penentu bahaya banjir menunjukkan bahwa: a) Bahaya banjir kelas rendah memiliki luasan 42.771 ha; b) Kelas sedang memiliki luas $48.034 \mathrm{ha}$; c) Kelas tinggi memiliki luas 28.767 ha. Kesesuaian pola ruang pada kawasan budidaya dengan kelas bahaya banjir menunjukkan bahwa kawasan
\end{abstract}

Received: September 02, 2020; Accepted: October 22, 2020; Available online: January 31, 2022

Copyright $\odot$ 2022, REGION: Jurnal Pembangunan Wilayah dan Perencanaan Partisipatif 
permukiman perdesaan pada kelas bahaya sedang memiliki luasan tertinggi sebesar 7.998 ha. Pada kelas bahaya tinggi, pertanian lahan basah memiliki luasan tertinggi yaitu 7.646 ha.

Kata Kunci: AHP; Bahaya; Banjir; RTRW

\begin{abstract}
Indonesia has natural conditions that are classified as prone to natural disasters. Disasters in Indonesia can be caused by both natural and human factors. The human factors occur when the land is used without considering the characteristics of the landscape. Kuningan Regency is one of the administrative areas affected by disasters (flood) due to land use that does not consider the landscape characteristic. The objective of this study is to find out the suitability between the spatial pattern of Kuningan Regency's Spatial Plan (2011-2031) and the flood area in Kuningan Regency. The methods used Analysis Hierarchy Process (AHP) and Pairwise Comparison to determine the score of flood and landslides factors, visual Sentinel imagery interpretation year 2018 to determine land use in Kuningan Regency and spatial analysis method through overlay technique to determine flood and landslide areas. The research results showed that the flood hazard factors that have the largest to the smallest weights according to the expert are rainfall, slope, land use, soil type, and elevation. Flood and landslide hazard is divided into 3 classes, which are low, medium, and high. The overlay result of flood factors showed that: a) Low class had an area of 42,771 ha; b) Medium class had an area of 48,034 ha; c) High class had an area of 28,767 ha. The suitability of spatial pattern in the cultivation area with the flood hazard class showed that the rural residential area is in the medium hazard class that had an area of 7,998 ha. In the high hazard class, wetland agriculture had the highest area of 7,646 ha.
\end{abstract}

Keywords: AHP; Flood; Hazard; Spatial Plan

\title{
1. Pendahuluan
}

Indonesia merupakan salah satu negara tropis dengan potensi alam yang melimpah. Meskipun demikian, Indonesia memiliki kondisi alam yang tergolong rawan terhadap bencana alam seperti longsor, gempa bumi, tsunami, kebakaran hutan, banjir, angin puting beliung, dan gunung api [1]. Frekuensi kejadian bencana di Indonesia terus mengalami peningkatan dari tahun ke tahun terutama yang berkaitan dengan bencana hidrometeorologi, seperti banjir, tanah longsor, kekeringan, kebakaran hutan, angin puting beliung dan gelombang pasang. Menurut BNPB [2], bencana hidrometeorologi terjadi rata-rata hampir $80 \%$ dari total bencana yang terjadi di Indonesia.

Deviana et al. [3] menyatakan bahwa kemunculan berbagai bencana di Indonesia lebih dipicu oleh kerusakan ekosistem alam dan pengabaian terhadap rencana tata ruang. Sementara itu, Suryanta dan Nahib [4] melihat bahwa kejadian bencana alam di Indonesia terjadi secara berulang, baik dari jenis yang sama maupun yang berbeda. Oleh sebab itu, program pengurangan resiko bencana di Indonesia menjadi perlu untuk diperkuat. Sejalan dengan hal 
tersebut Hygo Framework for Action (HFA), dalam Konferensi Pengurangan Risiko Bencana Dunia di Kobe pada tahun 2005, mengamanatkan bahwa perencanaan tata ruang harus berfungsi sebagai salah satu alat untuk pengurangan resiko bencana baik di negara maju maupun berkembang.

Perencanaan tata ruang di Indonesia sudah diatur dalam Undang-Undang No. 26 Tahun 2007 tentang Penataan Ruang [5]. Pada Rencana Tata Ruang Wilayah (RTRW) harus didasarkan pada aspek-aspek sosial, politik, ekonomi, budaya, teknologi, dan keadaan alam. Hal ini bertujuan agar dalam kegiatan pembangunan terjadi suatu interaksi antara manusia dengan alam yang serasi. RTRW harus berimplikasi untuk meningkatkan keamanan, kenyamanan, peningkatan produktivitas, dan menciptakan keharmonisan lingkungan hidup. Rencana tata ruang wilayah yang dimiliki oleh setiap kabupaten dan kota pada dasarnya harus berfungsi sebagai alat pengendali perubahan tata guna lahan. Namun pada prakteknya, proses perencanaan tata ruang wilayah yang terjadi saat ini masih sering berorientasi pada pertimbangan ekonomi, sehingga kepentingan-kepentingan ekologis sering kali kurang terakomodasi dengan baik [6].

Meskipun Kabupaten Kuningan tergolong sering mengalami bencana banjir, namun ketersediaan informasi spasial daerah bahaya bencana banjir dan longsor dirasakan masih kurang. Sedangkan menurut Miardini dan Saragih [7], pemetaan daerah bahaya adalah salah satu upaya pra bencana yang sangat bermanfaat sebagai early warning system karena dapat mengetahui lokasi mana yang rawan terhadap bencana dan kadar bahayanya. Informasi semacam ini sangat penting pula untuk perencanaan tata ruang maupun evaluasi terhadap kesesuaian pemanfaatan ruang. Hasil pemetaan dapat digunakan untuk menyusun suatu arahan penyempurnaan tata ruang guna menekan dampak bencana banjir di Kabupaten Kuningan.

Hasil penelitian Yamani [8] menggunakan metode Analisis Hirarki Proses (AHP) dalam penentuan daerah banjir Kabupaten Pidie menunjukkan hasil yang cukup baik berdasarkan hasil validasinya. Faktor-faktor yang mempengaruhi terjadinya banjir di suatu wilayah adalah curah hujan, penggunaan lahan, kemiringan lereng, jenis tanah dan elevasi. Berangkat dari itu, penelitian kali ini menggunakan metode AHP untuk menentukan daerah bahaya banjir di Kabupaten Kuningan. Faktor-faktor yang digunakan, yaitu curah hujan, kemiringan lereng, penggunaan lahan, jenis tanah dan elevasi. Selanjutnya, hasil daerah bahaya bencana banjir di evaluasi dengan Rencana Tata Ruang Wilayah Kabupaten Kuningan. Tujuan pada penelitian ini, antara lain: (1) menganalisis faktor penentu terjadinya banjir di Kabupaten Kuningan, (2) menentukan daerah bahaya bencana banjir di Kabupaten Kuningan, (3) menganalisis kesesuaian antara pola ruang RTRW Kabupaten Kuningan tahun 2011-2031 dengan daerah bahaya bencana banjir di Kabupaten Kuningan.

\section{Metode}

Penelitian dilaksanakan selama 6 bulan dimulai pada bulan Januari 2018 sampai bulan Juni 2018. Lokasi penelitian mencakup seluruh wilayah Kabupaten Kuningan, Jawa Barat. Penelitian ini menggunakan metode AHP dan metode spasial. Data yang digunakan dalam 
penelitian ini meliputi data primer dan data sekunder. Data primer dikumpulkan dari hasil wawancara dengan para ahli terkait bobot dan skor faktor-faktor penentu bahaya banjir dan longsor melalui kuesioner. Responden berjumlah 7 orang yang memiliki latar belakang dalam bidang kebencanaan, sumberdaya lahan/fisik, dan tata ruang. Data sekunder dikumpulkan dari berbagai instansi sesuai dengan atribut yang akan dikaji, yaitu dari a) BPBD Kabupaten Kuningan; b) Bappeda Kabupaten Kuningan; c) Dinas Pertanian Kabupaten Kuningan; dan d) BPS Kabupaten Kuningan. Data sekunder yang dikumpulkan berupa peta administratif, peta jenis tanah, peta curah hujan, peta penggunaan lahan, peta kemiringan lereng dan peta elevasi, peraturan/perundangan yang berlaku Peraturan Daerah Kabupaten Kuningan No 26 Tahun 2011 tentang Rencana Tata Ruang Wilayah Kabupaten Kuningan tahun 2011-2031 [9].

Data sekunder yang digunakan dalam penelitian ini, yaitu peta rencana pola ruang skala 1:50.000, peta administratif skala 1:50.000, peta jenis tanah skala 1:250.000, peta curah hujan 1:50.000, yang semuanya didapatkan di Bappeda Kabupaten Kuningan. Adapun peta penggunaan lahan Kabupaten Kuningan skala 1:50.000 diperoleh dari hasil interpretasi citra Sentinel yang didigitasi, sedangkan data DEM SRTM diperoleh dari website USGS. Data lain yang juga penting adalah data kejadian bencana Kabupaten Kuningan 3 tahun terakhir yaitu tahun 2015 - 2017 yang berasal dari BPBD [10].

Analisis AHP yang digunakan pada penelitian ini bertujuan untuk mendapatkan nilai bobot dan skor dari faktor penentu banjir dan longsor yang diperoleh dari responden dengan skala nilai mulai dari 1 sampai 9 melalui suatu perbandingan berpasangan (pairwise comparison). Kriteria penilaian dalam AHP disajikan pada Tabel 1.

Tabel 1. Kriteria penilaian dalam AHP [11].

\begin{tabular}{cl}
\hline Nilai & \multicolumn{1}{c}{ Keterangan } \\
\hline 1 & A sama penting dengan B \\
3 & A sedikit lebih penting dari B \\
5 & A jelas lebih penting dibanding B \\
7 & A sangat jelas lebih penting dari B \\
9 & A mutlak lebih penting dari B \\
$2,4,6,8$ & Apabila ragu-ragu antara dua nilai yang berdekatan \\
\hline
\end{tabular}

Sebelum hasil analisis AHP digunakan, maka perlu dilakukan penilaian terhadap konsistensi jawaban responden atau Consistency Index ( $\mathrm{Cl}$ ) agar dapat diperoleh nilai Consistency Ratio (CR) dari pakar/ahli yang memenuhi syarat. Rumus $C l$ dan $C R$ yang digunakan adalah sebagai berikut [12].

$$
\mathrm{Cl}=\frac{\lambda m a k s-n}{n-1}
$$

Dimana $: \mathrm{Cl}=$ Indeks Konsistensi; $\lambda$ maks = rata-rata skor; $\mathrm{n}=$ jumlah variabel

$$
\mathrm{CR}=\frac{\mathrm{CI}}{\mathrm{RI}}
$$

Dimana : $\mathrm{CR}=$ Nilai Inkonsistensi; $\mathrm{Cl}=$ Indeks Konsistensi; $\mathrm{RI}=$ Random index 
CR mampu mengukur seberapa besar konsistensi pengambil keputusan dalam membandingkan elemen-elemen dalam matrik penilaian [9]. Jika nilai $C R \leq 10 \%$, maka menunjukan tingkat konsistensi yang bagus, namun jika tidak maka data yang diperoleh tidak dapat digunakan atau perlu diperbaiki. Pengolahan data hasil wawancara ini dilakukan dengan bantuan software Expert Choice 2000.

Hasil pembobotan dan skoring tersebut selanjutnya di analisis dengan menggunakan persamaan Weighted Linear Combination (WLC) dan dispasialkan melalui sistem informasi geografis (SIG) yaitu software ArcGIS 10.4 untuk menghasilkan peta bahaya banjir di Kabupaten Kuningan. Persamaan WLC tersebut akan menghasilkan nilai baru yang secara menyeluruh sebagai bentuk dari kuantifikasi antara nilai faktor dan nilai subfaktor. Persamaan WLC yang digunakan adalah sebagai berikut [11]:

$$
W L C=\sum_{i=1}^{n} W_{i j} x X_{i j}
$$

Dimana: WLC $=$ Weighted Linear Combination; $W_{i j}=$ Derajat kesesuaian faktor/subfaktor ke-j dilokasi ke-i; $X_{i j}=$ bobot faktor/subfaktor ke-j di lokasi ke-I; n= Jumlah faktor

Tingkat bahaya pada penelitian kali ini dibagi menjadi 3 kelas, yaitu rendah, sedang, dan tinggi. Penentuan kelas bahaya dilakukan dengan membagi rata nilai-nilai bahaya dengan interval kelas yang sama (equal interval) dengan asumsi bahwa sebaran nilai bahaya bersifat normal. Jadi seluruh wilayah Kabupaten Kuningan memiliki kemungkinan bencana banjir dan longsor yang sama. Adapun nilai interval bahaya secara equal interval diperoleh melalui rumus seperti berikut.

$$
\text { Nilai interval kelas bahaya banjir/longsor }=\frac{\text { Nilai tertinggi-Nilai terendah }}{\text { Jumlah kelas bahaya }}
$$

Hasil penilaian bahaya dan persebaran spasialnya dengan perhitungan di atas selanjutnya perlu divalidasi. Validasi peta bahaya banjir dan longsor dilakukan dengan mengidentifikasi titik sebaran kejadian banjir berdasarkan kelas bahaya banjir dan longsor. Data sejarah kejadian bencana banjir dan longsor yang digunakan berupa laporan bencana yang diperoleh dari BPBD Kabupaten Kuningan berbasis batas administratif desa [10]. Data tersebut merupakan rekap bencana selama periode tahun 2015-2017. Pada hal ini 1 titik kejadian bencana mewakili 1 desa yang terkena dampak kejadian yang merupakan titik pusat desa atau centroid dalam GIS. Validasi menggunakkan titik pusat desa (centroid) merupakan pendekatan yang digunakan karena terbatasnya data luasan dampak bencana di Kabupaten Kuningan. Kegiatan analisis ini dilakukan melalui beberapa tahapan pekerjaan, yaitu:

a. Ekstraksi informasi penutup/penggunaan lahan Kabupaten Kuningan melalui interpretasi visual dari Citra Sentinel tahun 2018

b. Pengolahan DEM untuk menentukan kelas kelerengan dan elevasi sesuai dengan subfaktor yang telah ditentukan untuk Kabupaten Kuningan

c. Pengolahan data dengan metode AHP untuk mendapatkan nilai bobot dan skor 
d. Analisis spasial (SIG) melalui teknik overlay (tumpang tindih) antara peta jenis tanah, peta curah hujan, peta penggunaan lahan, peta kemiringan lereng dan peta elevasi/ketinggian

e. Pemetaan daerah bahaya banjir

Analisis kesesuaian antara bahaya bencana dan pola ruang RTRW Kabupaten Kuningan dilakukan dengan cara tumpang tindih (overlay) antara peta daerah bahaya bencana banjir dan longsor skala 1:50.000 dengan peta pola ruang. Fokus utama dalam analisis ini adalah pola ruang kawasan budidaya terutama pada kawasan permukiman dan kawasan ekonomi masyarakat karena dari kawasan ini diperkirakan akan mempunyai dampak yang cukup signifikan. Berdasarkan analisis ini akan diketahui ketidaksesuaian antara pemanfaatan ruang/pola ruang kawasan budidaya dan daerah bahaya bencana di Kabupaten Kuningan.

\section{Hasil penelitian dan pembahasan}

Faktor penentu banjir dalam penelitian ini mengacu pada Yamani [8], yaitu meliputi curah hujan, penggunaan lahan, jenis tanah, kemiringan lereng dan elevasi. Hasil perhitungan dari metode AHP untuk faktor penentu banjir disajikan pada Gambar 1. Berdasarkan Gambar 1 tersebut terlihat bahwa faktor penentu banjir yang mempunyai bobot paling tinggi adalah curah hujan sebesar 0.314 atau $31.4 \%$, diikuti oleh faktor kemiringan lereng dengan bobot sebesar 0.305 atau $30.5 \%$, faktor penggunaan lahan memiliki bobot sebesar 0.218 atau $21.8 \%$, dan faktor jenis tanah memiliki bobot sebesar 0.087 atau $8.7 \%$. Sedangkan, faktor penentu banjir paling rendah adalah faktor elevasi atau ketinggian dengan bobot sebesar 0.075 atau 7.5\%. Selain itu, untuk perhitungan nilai indeks konsistensi $(\mathrm{Cl})$ hasilnya menunjukkan angka nilai sebesar 0.04 atau 4\%. Maka dapat disimpulkan bahwa nilai inkonsistensi (CR) yaitu di bawah $10 \%$ yang artinya data analisis dapat digunakan dan jawaban pakar cukup konsisten.

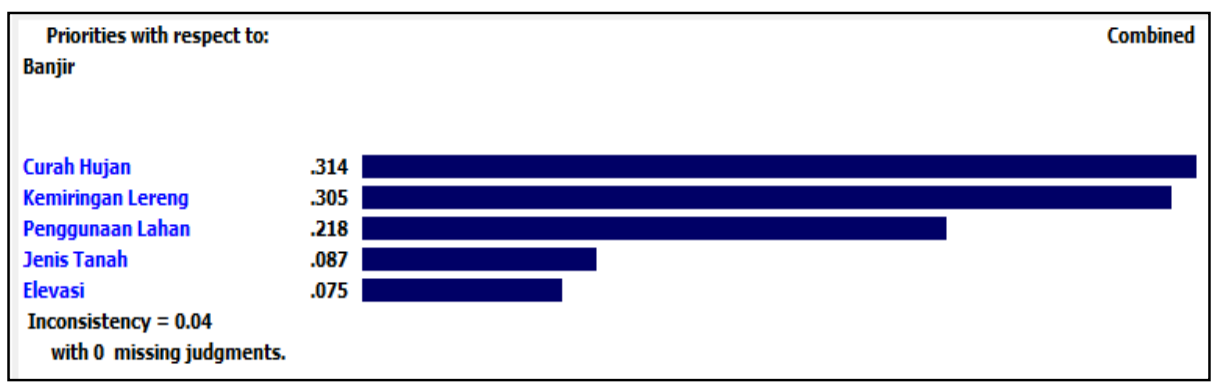

Gambar 1. Nilai bobot faktor penentu banjir.

Hasil jawaban para pakar tersebut menunjukkan bahwa faktor yang memiliki bobot tertinggi adalah curah hujan. Hal tersebut selaras dengan hasil penelitian Yamani [8] yang menyatakan bahwa banjir sangat dipengaruhi oleh kondisi curah hujan suatu wilayah yaitu semakin tinggi curah hujan suatu wilayah maka semakin tinggi potensi terjadinya banjir pada wilayah tersebut terutama untuk banjir lokal. Oleh karena itu, curah hujan merupakan salah satu parameter penyebab paling penting terjadinya banjir [13]. Menurut Aji [14], terdapat dua faktor penting yang menentukan bahaya atau tidaknya suatu daerah terjadi banjir, yaitu besarnya curah hujan dan kemiringan lereng. Adapun elevasi memiliki bobot terendah yang artinya bahaya banjir tidak bergantung sepenuhnya pada suatu ketinggian tempat. Hal ini 
dikarenakan banjir dapat terjadi pada dataran tinggi jika kondisi lereng dan faktor-faktor penentu banjir lainnya sangat mendukung untuk terjadinya banjir.

Berdasarkan hasil penilaian bobot dan skor untuk banjir, maka penilaian daerah bahaya banjir selanjutnya dapat diperoleh melalui persamaan di bawah ini yang menggambarkan perkalian antara nilai bobot faktor dengan skor subfaktor. Persamaan ini dinamakan Weighted Linear Combination (WLC) yang dapat diproses secara spasial menggunakan sistem informasi geografis (SIG) pada ArcGIS 10.4 .

$$
W L C=0.314 X_{1}+0.218 X_{2}+0.087 X_{3}+0.305 X_{4}+0.075 X_{5}
$$

Dimana: WLC $=$ Weighted Linear Combination; $X_{1}=$ Subfaktor Curah Hujan; $X_{2}=$ Subfaktor Penggunaan Lahan; $X_{3}=$ Subfaktor Jenis Tanah; $X_{4}=$ Subfaktor Kemiringan Lereng; dan $\mathrm{X}_{5}=$ Subfaktor Elevasi/ketinggian

Tabel 2. Hasil kalkulasi bahaya banjir.

\begin{tabular}{|c|c|c|c|c|c|}
\hline No & Faktor & Subfaktor & $\mathbf{W}$ & $\mathbf{X}$ & $\mathbf{W} * \mathbf{X}$ \\
\hline \multirow{3}{*}{1} & \multirow{3}{*}{$\begin{array}{l}\text { Curah Hujan } \\
\text { (mm/th) }\end{array}$} & $2000-2500$ & \multirow{3}{*}{0.314} & 0.260 & 0.082 \\
\hline & & $>2500-3000$ & & 0.327 & 0.100 \\
\hline & & $>3000$ & & 0.413 & 0.129 \\
\hline \multirow{7}{*}{2} & \multirow{7}{*}{$\begin{array}{l}\text { Penggunaan } \\
\text { Lahan }\end{array}$} & Hutan & \multirow{7}{*}{0.218} & 0.022 & 0.005 \\
\hline & & Kebun Campuran & & 0.052 & 0.011 \\
\hline & & Semak Belukar & & 0.081 & 0.018 \\
\hline & & Lahan Kosong & & 0.086 & 0.019 \\
\hline & & Sawah, Tegalan & & 0.205 & 0.045 \\
\hline & & Permukiman, Industri dan Bangunan & & 0.255 & 0.055 \\
\hline & & Tubuh Air & & 0.300 & 0.065 \\
\hline \multirow{7}{*}{3} & \multirow{7}{*}{ Jenis Tanah } & Aluvial Kelabu & \multirow{7}{*}{0.087} & 0.045 & 0.004 \\
\hline & & Asosiasi mediteran cokelat \& Litosol & & 0.049 & 0.004 \\
\hline & & Asosiasi Andosol cokelat \& Regosol cokelat & & 0.055 & 0.005 \\
\hline & & Regosol & & 0.087 & 0.008 \\
\hline & & Latosol & & 0.136 & 0.012 \\
\hline & & Podsolik, Regosol \& Latosol & & 0.192 & 0.017 \\
\hline & & Grumosol \& Regosol & & 0.434 & 0.037 \\
\hline \multirow{5}{*}{4} & \multirow{5}{*}{$\begin{array}{c}\text { Kemiringan } \\
\text { Lereng }\end{array}$} & $>40 \%$ & \multirow{5}{*}{0.305} & 0.031 & 0.009 \\
\hline & & $>15-40 \%$ & & 0.047 & 0.014 \\
\hline & & $>8-15 \%$ & & 0.089 & 0.027 \\
\hline & & $>2-8 \%$ & & 0.374 & 0.114 \\
\hline & & $0-2 \%$ & & 0.459 & 0.140 \\
\hline \multirow{6}{*}{5} & \multirow{6}{*}{ Elevasi } & $>1000 \mathrm{mdpl}$ & \multirow{6}{*}{0.075} & 0.033 & 0.003 \\
\hline & & $>450-1000 \mathrm{mdpl}$ & & 0.073 & 0.006 \\
\hline & & $>150-450 \mathrm{mdpl}$ & & 0.100 & 0.008 \\
\hline & & $>50-150 \mathrm{mdpl}$ & & 0.153 & 0.011 \\
\hline & & $>30-50 \mathrm{mdpl}$ & & 0.252 & 0.019 \\
\hline & & 0-30 mdpl & & 0.389 & 0.029 \\
\hline
\end{tabular}

Received: September 02, 2020; Accepted: October 22, 2020; Available online: January 31, 2022 Copyright @ 2022, REGION: Jurnal Pembangunan Wilayah dan Perencanaan Partisipatif 
Hasil analisis faktor dan subfaktor menunjukkan bahwa nilai bahaya banjir di Kabupaten Kuningan berkisar antara 0.003 (mempunyai elevasi $>1000$ mdpl) hingga 0.140 (mempunyai kemiringan lereng 0-2\%) (lihat Tabel 2). Hal tersebut dapat disimpulkan bahwa daerah dengan kemiringan lereng 0-2\% di Kabupaten Kuningan merupakan wilayah yang sangat mudah mengalami banjir atau dapat dikatakan bahwa semakin datar topografi suatu daerah maka semakin tinggi potensinya mengalami banjir. Sementara itu, untuk wilayah yang mempunyai elevasi >1000 mdpl memiliki potensi terjadi banjir yang semakin kecil.

Tabel 3. Pembagian kelas daerah bahaya bencana banjir beserta luasnya.

\begin{tabular}{cccc}
\hline \multirow{2}{*}{ Kelas Bahaya Banjir } & \multirow{2}{*}{ Interval } & Ha & Persen (\%) \\
\cline { 3 - 4 } & & 42771 & $35.77 \%$ \\
Rendah & $0.110-0.195$ & 48034 & $40.17 \%$ \\
Sedang & $0.195-0.281$ & 28767 & $24.06 \%$ \\
Tinggi & $0.281-0.367$ & 119572 & $100 \%$ \\
Jumlah & & & \\
\hline
\end{tabular}

Berdasarkan hasil penjumlahan diperoleh nilai tertinggi, yaitu sebesar 0.367 dan terendah sebesar 0.110. Tabel 3 menunjukkan bahwa Kabupaten Kuningan didominasi oleh kelas bahaya sedang yang memiliki luasan terbesar, yaitu 48.034 ha dengan persentase $40.17 \%$, diikuti oleh kelas bahaya banjir rendah sebesar 42.771 ha dengan persentase $35.77 \%$, dan kelas bahaya banjir tinggi sebesar 28767 ha dengan persentase 24.06\%. Berdasarkan keruangan, Kabupaten Kuningan bagian timur dan utara didominasi oleh daerah dengan kelas bahaya banjir tinggi, sedangkan bagian tengah didominasi oleh bahaya banjir sedang dan rendah. Sebaran spasial bahaya banjir dapat dilihat pada Gambar 2.

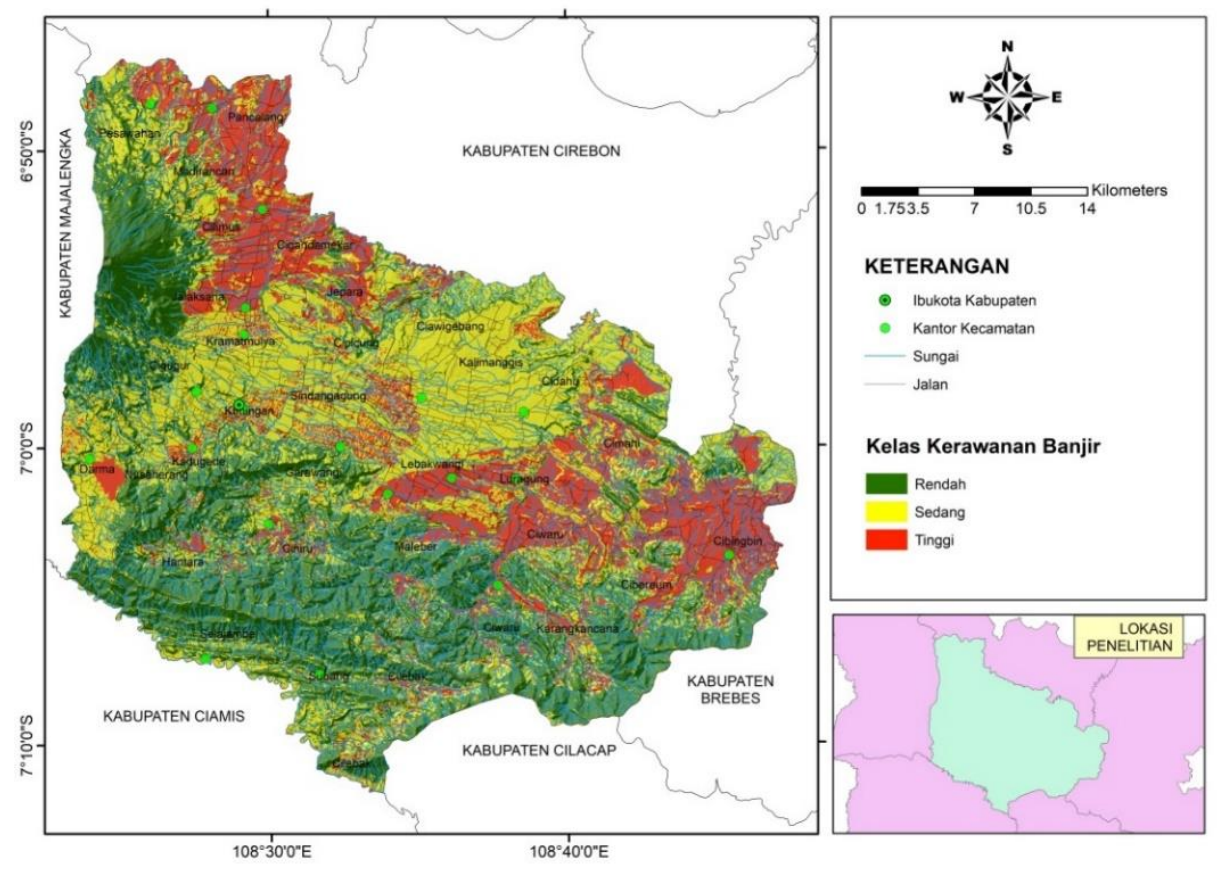

Gambar 2. Peta kelas bahaya banjir di Kabupaten Kuningan.

Received: September 02, 2020; Accepted: October 22, 2020; Available online: January 31, 2022

Copyright $\odot$ 2022, REGION: Jurnal Pembangunan Wilayah dan Perencanaan Partisipatif 
Hasil pengolahan data spasial kelas bahaya banjir di Kabupaten Kuningan menunjukkan sebarannya yang cukup variatif. Secara administratif, Kecamatan Karangkancana memiliki luasan paling tinggi untuk kelas bahaya rendah, yaitu sebesar 3.421 ha, Kecamatan Ciawigebang memiliki luasan tertinggi untuk kelas bahaya sedang sebesar 4.860 ha dan Kecamatan Cibingbin memiliki luasan paling tinggi untuk kelas bahaya tinggi sebesar 3509 ha.

Tabel 4. Validasi kejadian banjir berdasarkan sebaran bahaya bencana.

\begin{tabular}{ccccc}
\hline Kelas Bahaya Banjir & Luas (ha) & $\begin{array}{c}\text { Kejadian } \\
\text { Banjir }\end{array}$ & $\begin{array}{c}\text { Density } \\
\text { (ha/kejadian) }\end{array}$ & $\begin{array}{c}\text { Persentase } \\
\text { (\%) }\end{array}$ \\
\hline Rendah & 42771 & 4 & 10693 & 14.81 \\
Sedang & 48034 & 11 & 4367 & 40.17 \\
Tinggi & 28767 & 12 & 2397 & 44.44 \\
Jumlah & & 27 & & 100 \\
\hline
\end{tabular}

Hasil validasi peta bahaya banjir dengan data kejadian bencana banjir pada Tabel 4 menunjukkan bahwa dari total 27 titik sebaran kejadian banjir, terdapat sebanyak 12 titik kejadian atau $44.44 \%$ terjadi pada wilayah kelas bahaya banjir tinggi. Selain itu, terdapat sebanyak 11 titik kejadian yang terjadi pada wilayah dengan kelas bahaya sedang dan 4 titik kejadian pada kelas bahaya banjir rendah. Hasil analisis faktor dan subfaktor penentu menunjukkan bahwa kejadian bencana banjir sebanyak 4 (empat) kali yang terjadi pada kelas bahaya rendah umumnya merupakan daerah dengan kelerengan 0-2\% dengan curah hujan 2000-2500 mm/tahun dan tutupan lahan berupa belukar.

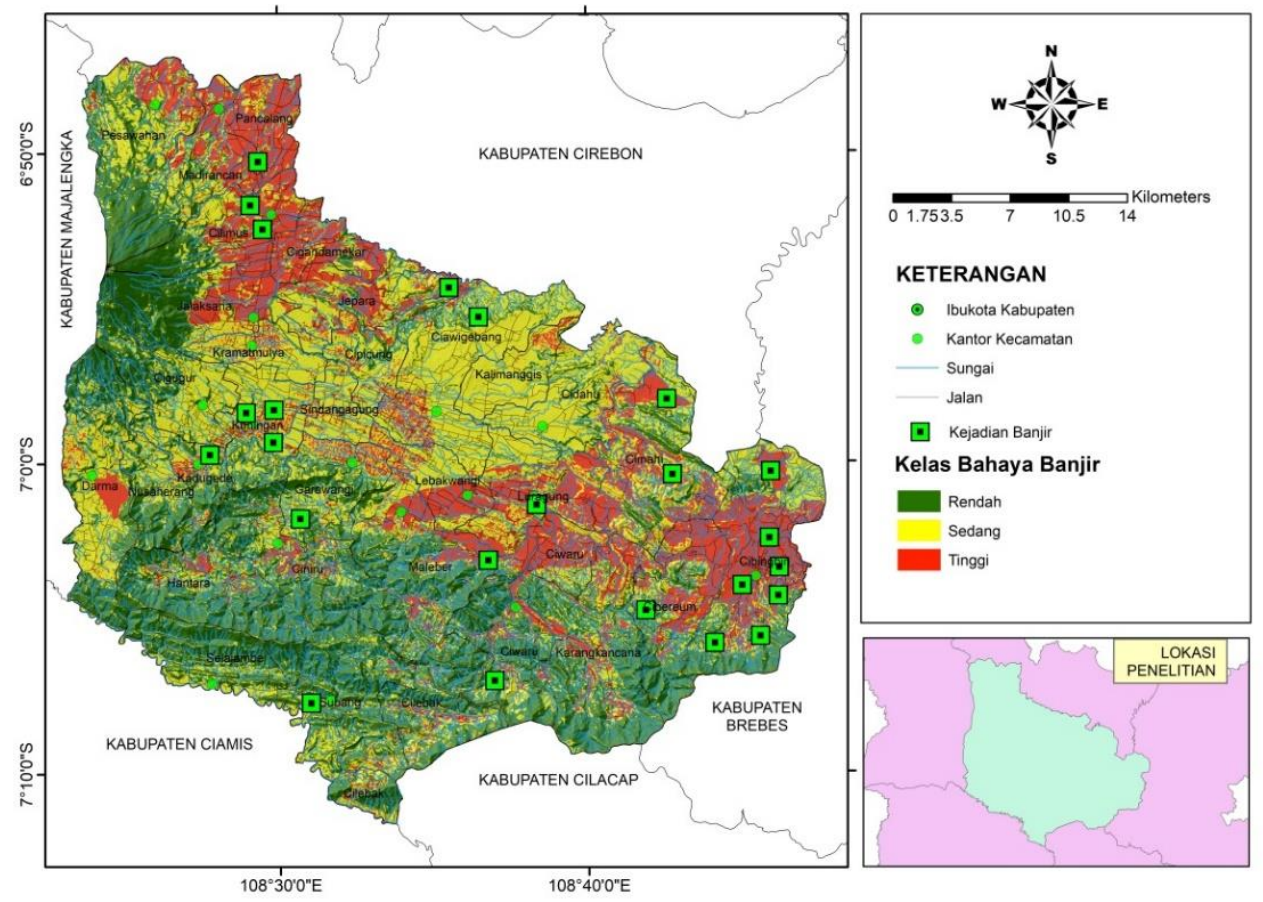

Gambar 3.1 Peta bahaya banjir dan persebaran titik-titik kejadian longsor tahun 2015-2017 di Kabupaten Kuningan untuk validasi. 
Hasil dari validasi cukup tinggi dikarenakan kerapatan (density) kejadian banjir menunjukkan bahwa semakin bahaya suatu wilayah maka kerapatan kejadian bencana semakin tinggi. Selain itu, secara keseluruhan hasil validasi menunjukkan tingkat validasi yang cukup tinggi jika dikaitkan dengan data sebaran titik kejadian banjir di Kabupaten Kuningan. Berdasarkan hasil spasial validasi, peta bahaya banjir dengan sebaran kejadian banjir periode tahun 20152017 dapat dilihat pada Gambar 3.

Tabel 5. Pola ruang kawasan lindung dan kawasan budidaya di Kabupaten Kuningan berdasarkan bahaya bencana banjir.

\begin{tabular}{lcccc}
\hline \multicolumn{1}{c}{ Kelas Bahaya Banjir } & $\begin{array}{c}\text { Kawasan } \\
\text { Lindung (ha) }\end{array}$ & $\begin{array}{c}\text { Persen } \\
\text { (\%) }\end{array}$ & $\begin{array}{c}\text { Kawasan } \\
\text { Budidaya (ha) }\end{array}$ & $\begin{array}{c}\text { Persen } \\
\text { (\%) }\end{array}$ \\
\hline Rendah & 21679 & 44.30 & 21092 & 29.86 \\
Sedang & 19249 & 39.33 & 28785 & 40.75 \\
Tinggi & 8009 & 16.37 & 20758 & 29.39 \\
Jumlah & 48937 & 100 & 70635 & 100 \\
\hline
\end{tabular}

Hasil overlay antara peta bahaya banjir dan peta pola ruang RTRW Kabupaten Kuningan ditunjukan pada Tabel 5. Pada kawasan lindung, kelas bahaya banjir rendah memiliki luasan tertinggi, yaitu sebesar 21.679 ha atau sebesar $44.30 \%$. Selanjutnya, kelas bahaya banjir sedang sebesar 19.249 ha sebesar $39.33 \%$ dan sisanya masuk ke dalam kelas bahaya banjir tinggi, yaitu seluas 8.009 ha atau $16.37 \%$. Pada kawasan budidaya, daerah bahaya banjir kelas sedang mendominasi kawasan ini, yaitu seluas 28.785 ha atau $40.75 \%$ dari total luas kawasan budidaya. Selanjutnya, diikuti oleh kelas bahaya banjir kelas rendah seluas 21.092 ha sebesar $29.86 \%$ dan bahaya banjir kelas tinggi seluas 20.758 ha sebesar $29.39 \%$. Daerah dengan bahaya banjir terluas pada kelas sedang dan tinggi di Kabupaten Kuningan terdapat di kawasan budidaya. Hal tersebut cukup menarik karena jika banjir terjadi di kawasan ini maka dampak banjir yang ditimbulkan bisa signifikan, sehingga perlu perhatian secara khusus oleh pemerintah daerah agar kesejahteraan hidup masyarakat dari sisi ekonomi, sosial, budaya dan lingkungan dapat terwujud secara selaras dengan mempertimbangkan mitigasi bencana banjir.

Pada kawasan permukiman perdesaan didapatkan luasan tertinggi bahaya banjir kelas sedang sebesar 7.999 ha dan memiliki luasan yang cukup tinggi untuk bahaya banjir kelas tinggi sebesar 6.744 ha. Adapun luasan tertinggi untuk bahaya banjir kelas tinggi adalah pada kawasan pertanian lahan basah sebesar 7.646 ha. Secara rinci luasan kelas bahaya banjir pada pola ruang tersaji pada Tabel 6. Hasil analisis menunjukkan bahwa pola ruang RTRW Kabupaten Kuningan masih memiliki ketidaksesuaian peruntukan kawasan yang seharusnya bebas dari daerah bahaya banjir terutama pada daerah dengan intensitas aktivitas manusia yang tinggi. Tingginya persentase luas pada kawasan permukiman untuk kelas bahaya banjir sedang dan tinggi yang dimungkinkan karena dalam perencanaan pembangunan kawasan permukiman berada pada daerah datar. Hal tersebut sejalan dengan penelitian Yamani [8] bahwa pada umumnya kawasan permukiman dibangun pada daerah dengan karakteristik topografi daerah datar sampai landai. 
Tabel 6. Pola ruang kawasan budidaya Kabupaten Kuningan ditinjau dari potensi bahaya bencana banjir.

\begin{tabular}{llccc}
\hline \multirow{2}{*}{ No } & \multirow{2}{*}{ Pola Ruang (RTRW) Kawasan Budidaya } & \multicolumn{3}{c}{ Luas Potensi Bahaya Banjir (ha) } \\
\cline { 3 - 5 } & Kendah & Sedang & Tinggi \\
\hline 1 & Kawasan Perkebunan Rakyat & 173 & 529 & 127 \\
2 & Kawasan Pertanian Hortikultura & 44 & 164 & 48 \\
3 & Kawasan Pertanian Pangan Lahan Basah & 837 & 5944 & 7646 \\
4 & Kawasan Pertanian Pangan Lahan Kering & 965 & 2677 & 1430 \\
5 & Kawasan Perikanan & 1 & 35 & 185 \\
6 & Kawasan Peternakan & 4 & 23 & 34 \\
7 & Kawasan Permukiman Perdesaan & 797 & 7999 & 6744 \\
8 & Kawasan Permukiman Perkotaan & 222 & 2490 & 1282 \\
Jumlah Kawasan Budidaya & 3043 & 19861 & 17495 \\
\hline
\end{tabular}

\section{Kesimpulan}

Berdasarkan hasil perhitungan menggunakan metode Analisis Hierarki Proses (AHP) menunjukkan bobot faktor penentu terjadinya bahaya banjir tertinggi di Kabupaten Kuningan adalah curah hujan sebesar $31.4 \%$, diikuti oleh kemiringan lereng sebesar $30.5 \%$, penggunaan lahan sebesar $21.8 \%$, jenis tanah sebesar $8.7 \%$ dan elevasi/ketinggian sebesar $7.5 \%$. Hasil pengolahan spasial daerah bahaya banjir menunjukkan bahwa Kabupaten Kuningan didominasi oleh kelas bahaya sedang yang memiliki luasan terbesar, yaitu 48.034 ha dengan persentase $40.17 \%$, diikuti oleh kelas bahaya banjir rendah sebesar 42.771 ha dengan persentase $35.77 \%$, dan kelas bahaya banjir tinggi sebesar 28.767 ha dengan persentase $24.06 \%$. Hasil pengolahan spasial peta bahaya banjir memiliki akurasi yang cukup baik karena hasil validasi menunjukan semakin bahaya suatu daerah, maka semakin tinggi nilai kerapatan kejadian bencananya. Kecamatan Cibingbin menjadi daerah dengan tingkat bahaya banjir tinggi terluas sebesar 3.509 ha dan Kecamatan Karangkancana memiliki daerah dengan tingkat bahaya rendah terluas sebesar 3.421 ha. Hasil analisis kesesuaian antara pola ruang RTRW Kabupaten Kuningan dengan daerah bahaya banjir menunjukkan bahwa masih tingginya luasan dengan kelas bahaya sedang dan tinggi pada kawasan budidaya, khususnya pada kawasan permukiman dan kegiatan ekonomi masyarakat. Oleh karena itu, pola ruang yang ada saat ini perlu dilakukan penyempurnaan berdasarkan bahaya banjir utamanya pada kawasan budidaya dengan intensitas kegiatan manusia yang tinggi demi menghindari dampak yang lebih besar akibat banjir.

\section{Referensi}

[1] Hikmah N, Barus B, Baskoro DPT. Studi Perbandingan Pemetaan Risiko Bencana Longsor Berbasis Pendekatan Normatif Dan Pendekatan Kuantitatif Di Kabupaten Garut. J Geogr Gea 2017;16:169-82. https://doi.org/10.17509/gea.v16i2.3558.g4183.

[2] Badan Nasional Penanggulangan Bencana. Data dan Informasi Bencana Indonesia 2014. http://dibi.bnpb.go.id/ (accessed January 8, 2020).

[3] Deviana A, Kridasantausa I, Yadi Suryadi. Kajian Pemodelan Spasial Banjir untuk Mendukung Kebijakan Sempadan Sungai dan Tata Ruang Wilayah (Studi Kasus 
Wilayah Pengembangan Baleendah) 2012.

[4] Suryanta J, Nahib I. Kajian Spasial Evaluasi Rencana Tata Ruang Berbasis Kebencanaan di Kabupaten Kudus Provinsi Jawa Tengah. Maj Ilm Globe 2016;18:33-42. https://doi.org/10.24895/MIG.2016.18-1.392.

[5] Republik Indonesia. Undang-Undang Nomor 26 Tahun 2007 Tentang Penataan Ruang 2007.

[6] Pribadi DO, Shiddiq D, Ermyanila M. Model perubahan tutupan lahan dan faktor-faktor yang mempengaruhinya. J Tek Lingkung P3TLBPPT 2006;7:35-51. https://doi.org/10.29122/jtl.v7i1.364.

[7] Miardini A, Saragih GS. PENENTUAN PRIORITAS PENANGANAN BANJIR GENANGAN BERDASARKAN TINGKAT KERAWANAN MENGGUNAKAN TOPOGRAPHIC WETNESS INDEX Studi Kasus di DAS Solo. J Ilmu Lingkung 2019;17:113-9. https://doi.org/10.14710/jil.17.1.113-119.

[8] Yamani A, Rustiadi E, Widiatmaka. Evaluasi Pola Ruang Berbasis Kerawanan Banjir di Kabupaten Pidie. J Tata Loka 2015;17:130-47. https://doi.org/10.14710/tataloka.17.3.130-146.

[9] Pemkab Kuningan. Peraturan Daerah Kab. Kuningan No 26 Tahun 2011 tentang Rencana Tata Ruang Wilayah Kabupaten Kuningan tahun 2011-2031 2011.

[10] Badan Penanggulangan Bencana Daerah Kabupaten Kuningan. Laporan Bencana Tahunan Kabupaten Kuningan 2018. https://bpbd.kuningankab.go.id/info-bencanatahunan/2017 (accessed February 18, 2019).

[11] Saaty TL, Kirti PI, Liana S. Pengambilan Keputusan Bagi Para Pemimpin Proses Hirarki Analitik untuk Pengambilan Keputusan Dalam Situasi yang Komplek. Jakarta: Pustaka Binaman Pressindo; 1993.

[12] Falatehan AF. Analytical Hierarchy Process (AHP) Teknik Pengambilan Keputusan Untuk Pembangunan Daerah. Yogyakarta: Indomedia Pustaka; 2016.

[13] Budiarti W, Gravitiani E, Mujiyo. Analisis Aspek Biofisik Dalam Penilaian Kerawanan Banjir Di Sub Das Samin Provinsi Jawa Tengah. J Pengelolaan Sumberd Alam Dan Lingkung 2018;8:96-108. https://doi.org/10.29244/jpsl.8.1.96-108.

[14] Aji MD, Sudarsono B, Sasmito B. Identifikasi Zona Rawan Banjir Menggunakan Sistem Informasi Geografis (Studi Kasus: Sub Das Dengkeng). J Geod Undip 2014;3:36-50. 